\title{
Temperature-Dependent Shift of Balance among the Components of Short-Term Plasticity in Hippocampal Synapses
}

\author{
Vitaly A. Klyachko and Charles F. Stevens \\ Howard Hughes Medical Institute and Molecular Neurobiology Laboratory, The Salk Institute, La Jolla, California 92037
}

\begin{abstract}
Studies of short-term plasticity (STP) in the hippocampus, performed mostly at room temperature, have shown that small central synapses rapidly depress in response to high-frequency stimulation. This decrease in synaptic strength with synapse use places constraints on the use of STP as a dynamic filter for processing of natural high-frequency input. Here we report that, because of a strong but differential temperature dependence of STP components, the properties of STP in excitatory hippocampal synapses change dramatically with temperature. By separating the contributions of various STP processes during spike trains at different temperatures, we found a shift from dominating depression at $23^{\circ} \mathrm{C}$ to prevailing facilitation and augmentation at $33-38^{\circ} \mathrm{C}$. This shift of balance among STP components resulted from a large increase in amplitudes of facilitation and augmentation $\left(Q_{10} \sim 2.6\right.$ and $\sim 5.1$, respectively $)$ and little change in the amplitude of depression $\left(Q_{10} \sim 1.1\right)$ with temperature. These changes were accompanied by the accelerated decay of all three processes $\left(Q_{10}=3.2,6.6\right.$, and 2.1, respectively). The balance of STP components achieved at higher temperatures greatly improved the maintenance of synaptic strength during prolonged synaptic use and had a strong effect on the processing of natural spike trains: a variable mixture of facilitated and depressed responses at $23^{\circ} \mathrm{C}$ changed into a significantly more reproducible and depression-free filtering pattern at $33-38^{\circ} \mathrm{C}$. This filtering pattern was highly conserved among cells, slices, and animals, and under various physiological conditions, arguing for its physiological significance. Therefore, the fine balance among STP components, achieved only at near body temperatures, is required for the robust function of STP as a dynamic filter during natural stimulation.
\end{abstract}

Key words: short-term synaptic plasticity; temperature dependence; natural stimulation patterns; synaptic filtering; information processing; hippocampus

\section{Introduction}

During ongoing activity, synaptic transmission is rapidly and dynamically modulated in a history-dependent manner. This shortterm plasticity (STP) is thought to play a major role in information processing (Zucker and Regehr, 2002). Although properties of individual STP components have been studied extensively, the difficulty in analyzing the complex interplay of multiple forms of STP during the processing of realistic spike trains (Varela et al., 1997; Dobrunz and Stevens, 1999; Dittman et al., 2000; OhligerFrerking et al., 2003) hinders an understanding of their roles in synaptic computations at the majority of synapses. As a result, the function of STP has been characterized only in a few specific cases in which a single STP component dominates the synaptic response (Abbott et al., 1997; Tsodyks and Markram, 1997; Chung et al., 2002; Cook et al., 2003). An analysis introduced in studies of STP in the neuromuscular junction (Magleby, 1979; Magleby

Received Jan. 5, 2006; revised May 24, 2006; accepted May 24, 2006.

We thank Drs. Robert Muller and Andre Fenton for generously providing the natural spike patterns. We also thank Dr. Khuloud Jaqaman for help with data analysis and Drs. Edward Han, Khuloud Jaqaman, and Juan Pina-Crespo for the critical comments on this manuscript.

Correspondence should be addressed to Vitaly A. Klyachko, Molecular Neurobiology Laboratory, The Salk Institute, 10010 North Torrey Pines Road, La Jolla, CA 92037. E-mail: klyachko@salk.edu.

DOI:10.1523/JNEUROSCI.1382-06.2006

Copyright $\odot 2006$ Society for Neuroscience $\quad$ 0270-6474/06/266945-13\$15.00/0 and Zengel, 1982; Kalkstein and Magleby, 2004), in which parameters of STP components were dissected from the decay phase of STP, can potentially circumvent this problem by separating contributions of overlapping components. Despite the importance of such an analysis for understanding STP function, it has not yet been attempted for CNS synapses. The goal of our study is to extend this approach for the analysis of STP components in small CNS synapses and to elucidate how the balance among these processes determines STP function during the processing of relevant spike trains.

Hippocampal CA3-CA1 synapses, used as a model system in our study, are one of the most well studied examples of CNS synapses expressing a mixture of multiple STP processes. Nevertheless, elucidating the role of STP in these synapses has been complicated by the fact that no strong correlation between the input spike pattern and the resulting synaptic response has been observed (Dobrunz and Stevens, 1999). The work cited above, however, as well as many other studies of hippocampal STP, has been performed at room temperature. A number of recent studies have shown that synaptic transmission can be affected dramatically by changes in temperature on both physiological and structural levels (Hardingham and Larkman, 1998; Dinkelacker et al., 2000; Taschenberger and von Gersdorff, 2000; Volgushev et al., 2000; Pyott and Rosenmund, 2002; Fernandez-Alfonso and 
Ryan, 2004; Roelandse and Matus, 2004; Micheva and Smith, 2005; Kushmerick et al., 2006). These findings suggest that contributions of different STP components, and the resulting computations performed by STP, may change significantly with temperature.

Here we have separated contributions of all major STP components expressed in excitatory hippocampal synapses to investigate how their roles in the processing of constant frequency and natural stimulation patterns change with temperature. Our data reveal a shift among STP components from dominating depression at $23^{\circ} \mathrm{C}$ toward prevailing facilitation and augmentation at $33-38^{\circ} \mathrm{C}$. This shift greatly improves the maintenance of synaptic strength during high-frequency stimulation and has a strong effect on the processing of natural spike patterns. Our results indicate that a fine balance among STP components, achieved only at near physiological temperatures, is required for a robust and physiologically relevant STP function during natural stimulation.

\section{Materials and Methods}

Preparation. Transverse hippocampal slices $(400 \mu \mathrm{m})$ were prepared from 14- to 25-d-old (for whole-cell recordings) or 21- to 35-d-old (for field potential recordings) Long-Evans rats as described previously (Pouille and Scanziani, 2001; Losonczy et al., 2002). In brief, slices were cut on a Leica Vibratome in ice-cold, modified ACSF containing (in mM): $85 \mathrm{NaCl}, 75$ sucrose, $2.5 \mathrm{KCl}, 1.25 \mathrm{NaH}_{2} \mathrm{PO}_{4}, 26 \mathrm{NaHCO}_{3}, 0.5 \mathrm{CaCl}_{2}, 4$ $\mathrm{MgCl}_{2}, 13$ glucose, bubbled with $95 \% \mathrm{O}_{2} / 5 \% \mathrm{CO}_{2}$. Slices were incubated for $\sim 1 \mathrm{~h}$ at $32-33^{\circ} \mathrm{C}$ and then held at the room temperature for $0-4 \mathrm{~h}$ before recordings in standard ACSF solution, of the same composition as above, but with $120 \mathrm{NaCl}, 2 \mathrm{CaCl}_{2}, 1 \mathrm{MgCl}_{2}$ (unless noted otherwise) and no sucrose. The CA3 region was surgically separated in each slice with incision to prevent recurrent excitation.

Electrophysiological recordings. Schaffer collaterals were stimulated (100 $\mu \mathrm{s} ; 50-200 \mu \mathrm{A}$ current injections) via a bipolar electrode placed in the stratum radiatum, and either whole-cell currents or extracellular field potentials were recorded using an Axopatch 200B amplifier. EPSCs were recorded from CA1 pyramidal cells at the holding potential of $-74 \mathrm{mV}$ unless noted otherwise. Micropipettes (3-6 M $\Omega$ ) were filled with solution containing (in mM): $130 \mathrm{~K}$-gluconate, $10 \mathrm{KCl}, 9 \mathrm{NaCl}, 10 \mathrm{HEPES}, 5$ EGTA, 2.5 MgATP, 0.3 LiGTP; pH 7.25, 290-300 mOsm. Membrane holding potentials were corrected a posteriori for liquid junction potential $(\sim 14 \mathrm{mV})$. Access resistance was monitored continuously, and cells with unstable access resistance $(>20 \%$ change) were excluded from analysis. Field EPSP (fEPSP) recordings were made in a submerged chamber with the recording electrode positioned in the stratum radiatum, twothirds of the way into dendritic tree area, and filled with solution of the same composition as standard ACSF, but with $20 \mathrm{HEPES}, 0 \mathrm{NaH}_{2} \mathrm{PO}_{4}, 0$ $\mathrm{NaHCO}_{3}, \mathrm{pH}$ adjusted to 7.25. All recordings were made in the presence of the $\mathrm{GABA}_{\mathrm{A}} \mathrm{R}$ antagonist picrotoxin $(100 \mu \mathrm{M})$ or the more specific $\mathrm{GABA}_{\mathrm{A}} \mathrm{R}$ antagonist gabazine $(10 \mu \mathrm{M})$ to block inhibitory responses and the NMDA receptor antagonist aminophosphonopentanoic acid (50 $\mu \mathrm{M})$ to prevent possible long-term effects.

Temperature measurement and control. Bath temperature in the recording chamber was monitored continuously with a bead thermistor probe positioned within $<5 \mathrm{~mm}$ from the slice. The probe provided a feedback reading for the automatic heater controller that continuously adjusted the temperature to a desired setting via an in-line solution heater positioned immediately before the recording chamber. For any temperature setting, slices were kept for $20 \mathrm{~min}$ at the desired temperature before the first control baseline measurements were started. With several additional minutes used to establish a baseline and $\sim 2 \min$ of control recordings at $0.1 \mathrm{~Hz}$ separating each train, the first actual recording was made after $\sim 25 \mathrm{~min}$. The $25 \mathrm{~min}$ waiting time was sufficient to establish stable recordings at all temperatures because synaptic responses were highly repeatable for the duration of recordings. To reduce variability associated with small changes in temperature during recordings $\left(<0.5^{\circ} \mathrm{C}\right)$, parameters of STP components were measured multiple times in each slice and in random order.

Separation of STP components. To estimate the parameters of STP components, constant-frequency trains of $10-150$ stimuli at $2-40 \mathrm{~Hz}$ were used. The amplitude and time course of each component were determined sequentially, starting with the slowest one, by selecting an appropriate time window, when that component dominated the synaptic response (see Fig. 2). For each train presentation, synaptic responses were normalized to an average of five control responses immediately preceding the train. Responses to four to six train presentations were averaged for each stimulation protocol. Parameters of each component were estimated using the monoexponential Levenberg-Marquardt least squares fitting algorithm in Origin and later used to compensate, where necessary, for the contributions of that component to the mixture with the faster STP processes (see Fig. 2). This approach is based on an analysis introduced in the studies of STP in the neuromuscular junction (NMJ) (Magleby and Zengel, 1976a, 1982; Kalkstein and Magleby, 2004), in which normalized synaptic response can be described as follows (see Fig. 2):

$$
\mathrm{EPSP} / \mathrm{EPSP}_{0}=(1+F)(1+A U G)(1-D E P) .
$$

A multiplicative relationship between the components of potentiation and depression arises if these processes act independently to modulate the transmitter release, as has been suggested previously (Magleby and Zengel, 1976a; Magleby, 1979; Varela et al., 1997; Dittman et al., 2000; Zucker and Regehr, 2002; Abbott and Regehr, 2004; Kalkstein and Magleby, 2004). A multiplicative relationship between different forms of potentiation is suggested by previous studies in the NMJ (Magleby, 1979; Magleby and Zengel, 1982; Kalkstein and Magleby, 2004),.

In this approach, parameters of augmentation $(A U G)$ were determined in the time window of $5-30 \mathrm{~s}\left(10-60 \mathrm{~s}\right.$ at $\left.23^{\circ} \mathrm{C}\right)$ after the end of the train, when faster STP components, i.e., facilitation $[\tau \sim 150 \mathrm{~ms}(\sim 500$ $\mathrm{ms}$ at $\left.\left.23^{\circ} \mathrm{C}\right)\right]$ and depression $\left[\tau \sim 1.2 \mathrm{~s}\left(\sim 2.5 \mathrm{~s}\right.\right.$ at $\left.\left.23^{\circ} \mathrm{C}\right)\right]$, have decayed completely. In some cases, when measurable amounts of a very slow component of depression ( $\tau \sim 50-60 \mathrm{~s}$ ) (Stevens and Wesseling, 1999) were observed, the decay of $A U G$ was corrected for the very slow depression, assuming a multiplicative relationship between the components and taking into account that in the selected time window $F=0, D E P=0$ and calculating the amplitude of the very slow depression for each time point assuming monoexponential kinetics of decay. For the majority of stimulation paradigms used in this study, however, including all natural spike trains, the amplitude of the very slow depression was negligible and therefore did not contribute significantly to the temperature-dependent shift in synaptic response observed with all stimulus trains.

The kinetics of the rapid depression $(D E P)$ was studied with a separate set of measurements by applying a single test pulse at different intervals $\left[250 \mathrm{~ms}\left(500 \mathrm{~ms}\right.\right.$ at $\left.23^{\circ} \mathrm{C}\right)$ to $6 \mathrm{~s}\left(8 \mathrm{~s}\right.$ at $\left.\left.23^{\circ} \mathrm{C}\right)\right]$ after a 150 -stimulus train at 10 or $40 \mathrm{~Hz}$. Every time point was measured at least twice in each slice. Recovery from $D E P$ was contaminated mostly by decaying facilitation and augmentation. To minimize the contribution from overlapping but rapidly decaying facilitation, the first time point was recorded at $250 \mathrm{~ms}$ at $33^{\circ} \mathrm{C}$ and at $500 \mathrm{~ms}$ at $23^{\circ} \mathrm{C}$. Contributions from overlapping facilitation (determined with a paired-pulse protocol; see below) and augmentation were compensated using Equation 1 and assuming a multiplicative relationship among the components, as described above. In the selected time window, the contribution from the very slow component of depression (with $\tau \sim 50-60 \mathrm{~s}$ ) to the kinetics of the recovery from depletion $(\tau$ $\sim 1-2 \mathrm{~s}$ ) was negligible and was not corrected for.

Parameters of facilitation $(F)$ were estimated with the commonly used paired-pulse protocol, which is insufficient to evoke other forms of STP (see Fig. 4) (Zucker and Regehr, 2002).

We also confirmed that the kinetics-based separation of STP components described above was consistent with a more direct approach, in which the entire data recorded after the stimulus train was fitted with Equation 1 directly. In these calculations we set $F=0$, because facilitation had mostly decayed by the time the first data point for the recovery from depression was recorded, several hundred milliseconds after the train. This analysis produced results for the temperature-dependent changes in 

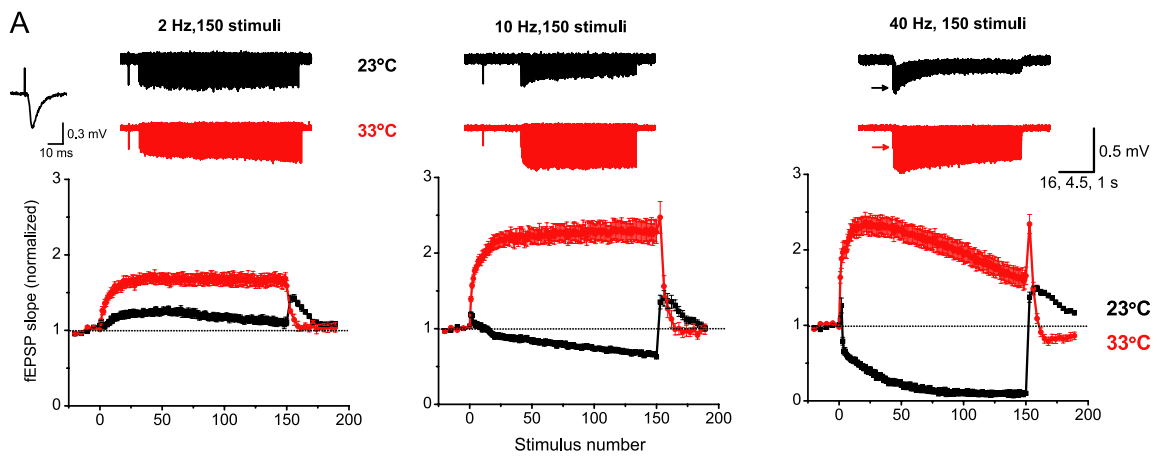

B
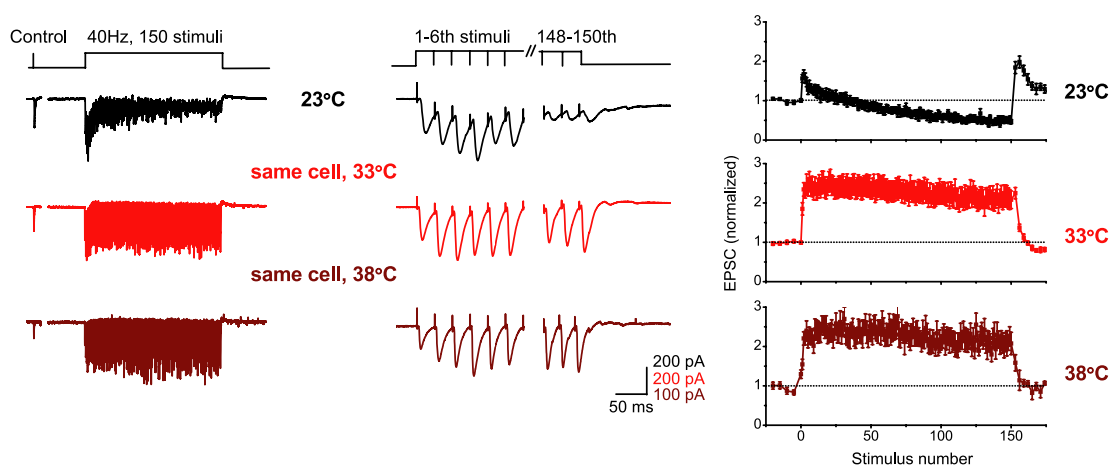

Figure 1. Temperature-dependent shift from depression to potentiation. $A$, Top, Representative examples of raw fEPSP train responses at $23^{\circ} \mathrm{C}$ (black) and at $33^{\circ} \mathrm{C}$ (red) evoked by 150 -stimulus trains at 2, 10 , and $40 \mathrm{~Hz}$. For presentation only, traces were downsampled, and the baseline drifts were corrected as described in Materials and Methods. The last control fEPSP, recorded at $0.1-0.2 \mathrm{~Hz}$ immediately preceding each train, is shown for 2 and $10 \mathrm{~Hz}$ trains or indicated by an arrow for $40 \mathrm{~Hz}$ trains. Bottom, Average normalized initial fEPSP slopes (here and throughout) are plotted versus stimulus number in the train for 2,10 , and $40 \mathrm{~Hz}$ ( $n=9-16$ slices). Inset, An example of a typical fEPSP. B, An example of whole-cell EPSC responses evoked in a CA1 pyramidal neuron by $40 \mathrm{~Hz}$, 150 -stimulus trains at $23^{\circ} \mathrm{C}$ (black traces), $33^{\circ} \mathrm{C}$ (red traces), and $38^{\circ} \mathrm{C}$ (brown traces) (left panels). The first six and the last three EPSCs from each train are shown on an expanded timescale for each temperature (middle panels). Average EPSC amplitudes at 23,33 , and $38^{\circ} \mathrm{C}(n=11$ cells) are plotted versus stimulus number for each temperature (right panels).

depression and augmentation very similar to those observed with the first method, with $\mathrm{Q}_{10}=1.1$ and 3.6 for the amplitudes and $\mathrm{Q}_{10}=2.3$ and 6.0 for the time-constants of depression and augmentation, respectively.

Data analysis and presentation. Data were analyzed using software written in Matlab. Both peak amplitudes and initial slopes were analyzed and compared for consistency. Peak amplitudes were used for EPSCs, and initial slopes were used for fEPSPs. Peak amplitudes were measured relative to the baseline, which was calculated as an average of five points (1 ms) immediately preceding each spike. To account for the overlap of currents or potentials, which occurs mostly during natural stimulation at short interspike intervals (ISIs), the following method was applied to each set of responses to a stimulus train presentation and 6-8 preceding control measurements: first, a template of EPSC or fEPSP waveform was created by averaging responses separated by at least $100 \mathrm{~ms}$ from their neighbors and normalized to their peak values. For all ISIs $<40 \mathrm{~ms}$, two previous responses were approximated by a template waveform scaled to their peaks, and the contributions to the current response were subtracted. Because of the rapid time course of EPSC and EPSP decay, the contribution from the third preceding response during high-frequency epochs was indistinguishable from noise for all types of recordings. All data are presented as mean \pm SEM. Statistical significance was evaluated using two-tailed $t$ test.

For presentation only, the raw traces of spike train responses several seconds in duration (see Figs. 1, 5, 7) were down-sampled 4-10 times, and the baseline drifts were corrected either by using the method of moving average ( 2 and $10 \mathrm{~Hz}$ data) or by calculating an average for $1 \mathrm{~ms}$ intervals immediately preceding each spike and subtracting it from each ISI ( $40 \mathrm{~Hz}$ data).

Natural spike patterns. The natural stimulation patterns used here represent timings of action potential firing recorded in vivo from the hip- pocampal place cells of awake, freely moving rats [generously provided by Drs. A. A. Fenton and R. U. Muller (Fenton and Muller, 1998)]. Six different patterns of 128 stimuli were used. Natural stimulation patterns were presented multiple times to the same cell or slice, separated by $2-3$ min control sections at $0.1-0.2 \mathrm{~Hz}$ Each subset of data was normalized to an average of four to six control responses immediately preceding each train. Spikes with ISIs $<10 \mathrm{~ms}$ were treated as a single stimulus, because the delay between the action potential firing and the peak of postsynaptic currents (potentials) prevented resolution of individual synaptic responses at shorter ISIs.

\section{Results \\ Temperature-dependent shift from depression to potentiation}

Our basic findings are illustrated in Figure $1 A$, in which we compare fEPSPs evoked in the CA1 area of the hippocampus by a series of constant-frequency trains at 2-40 $\mathrm{Hz}$ at room temperature $\left(23^{\circ} \mathrm{C}\right)$ and at near physiological temperature $\left(33^{\circ} \mathrm{C}\right)$. In agreement with previous studies (Dobrunz and Stevens, 1997; Brager et al., 2002; Sun et al., 2005), the synaptic response at room temperature consisted of a small initial increase in amplitude that was rapidly overcome by accumulating depression ( $n=9-16$ slices) (Fig. $1 A$, black traces). The relative contribution of apparent depression (estimated as a difference between the maximal response and the minimal response during the train, normalized by the maximal response) increased with the frequency of stimulation from $10 \pm 3 \%$ at $2 \mathrm{~Hz}$ to $45 \pm 2 \%$ at $10 \mathrm{~Hz}$, reaching $96 \pm 4 \%$ at $40 \mathrm{~Hz}$ (Figs. $1 A, 3 C$ ). In contrast, high-frequency stimulation at $33^{\circ} \mathrm{C}$ evoked a large increase in synaptic strength that persisted throughout the train at all frequencies tested (Fig. $1 A$, red traces). No significant depression was evident at frequencies $<10 \mathrm{~Hz}$, and even at $40 \mathrm{~Hz}$, slowly accumulating depression $(32 \pm 4 \%, n=16$ ) was mostly countered by synaptic potentiation (Fig. $1 \mathrm{~A}$, right panel) (compare with $96 \%$ of depression at $23^{\circ} \mathrm{C}$ ). These data show that the balance among STP components shifts with temperature from the dominating depression at room temperature toward potentiation at near physiological temperatures.

Because fEPSP recordings represent a combined response from many cells, we sought to confirm these findings in individual CA1 neurons with the whole-cell recordings. Using minimal stimulation, we first confirmed the previous observations that different forms of STP coexist in putative single CA3-CA1 synapses (supplemental Fig. 1, available at www.jneurosci.org as supplemental material) (Dobrunz and Stevens, 1997). Next, we used multifiber stimulation at different temperatures to evaluate the temperature-dependent changes in STP during highfrequency trains. Figure $1 B$ shows an example of whole-cell currents evoked in the same neuron by a $40 \mathrm{~Hz}, 150$-stimulus train at three different temperatures: 23,33 , and $38^{\circ} \mathrm{C}$. As in fEPSP recordings, the initial increase in the EPSC amplitude at $23^{\circ} \mathrm{C}$ was dominated by accumulating depression, which caused synaptic responses to decline rapidly ( $n=11$ cells) (Fig. $1 B$, black traces) 
(fEPSP and EPSC train responses are also shown on an expanded time scale in supplemental Fig. 2, available at www.jneurosci.org as supplemental material). At 33 and $38^{\circ} \mathrm{C}$, however, responses showed large increases in amplitude that persisted throughout the train (Fig. 1B, red traces). Again, accumulation of apparent depression during trains proceeded much faster at room temperature, increasing with frequency of stimulation from $12 \pm 5 \%$ at $2 \mathrm{~Hz}$ to $29 \pm 6 \%$ at $10 \mathrm{~Hz}$, and reaching $75 \pm 4 \%$ at $40 \mathrm{~Hz}$ (but only $17 \pm 4 \%$ at $33^{\circ} \mathrm{C} ; p<10^{-12}$ ) [supplemental Fig. $3 A$, available at www.jneurosci.org as supplemental material $(n=7-11$ cells; two to five train presentations per cell)].

These data show that the results reported by whole-cell and fEPSP recordings are basically similar, with the fEPSPs representing averaged whole-cell responses from multiple cells [the somewhat larger extent of apparent depression observed in fEPSP recordings may reflect the age difference of the animals used for whole-cell and fEPSP recordings (14-25 vs 21-35 d old, respectively) (Bolshakov and Siegelbaum, 1995; Hsia et al., 1998; Dekay et al., 2006)]. Therefore, the temperature-dependent shift among STP components is a robust effect that occurs both in single cells as well as in large populations of cells. In the experiments described below, we further confirmed that results reported by whole-cell and fEPSP recordings are equivalent for all of our major findings. Because this study required experiments with multiple train presentations and hours of continuous recordings, the experiments described below were typically performed using the more stable fEPSP recordings, with the key observations (data in Figs. 1, 3, 7, 8, and 9) being confirmed by whole-cell recordings.

As seen in Figure $1 \mathrm{~B}$, synaptic responses at 33 and $38^{\circ} \mathrm{C}$ were qualitatively similar, with only a slight difference in the magnitude of increase during trains. Thus, most of the shift from depression to potentiation occurred in the range of $23-33^{\circ} \mathrm{C}$. A detailed analysis of the STP temperature dependence presented below confirmed this observation by showing that parameters of all STP components changed mostly in the $23-33^{\circ} \mathrm{C}$ temperature range but did no change significantly between 33 and $38^{\circ} \mathrm{C}$ (see Fig. 6). Because maintaining healthy slices at $38^{\circ} \mathrm{C}$ for prolonged periods of time is difficult as a result of oxygen escape from the solution at this temperature, we performed most of the hightemperature recordings at $33^{\circ} \mathrm{C}$. The above observations gave us confidence that recordings made at $33^{\circ} \mathrm{C}$ accurately reflected properties of synaptic transmission at body temperature. As an additional control, however, we also confirmed the key observations at $38^{\circ} \mathrm{C}$ (Figs. 1, 3-8).

Postsynaptic recordings may reflect not only presynaptic changes attributable to STP, but they may also reflect several postsynaptic effects, such as receptor saturation and desensitization. We tested whether these processes could play an appreciable role in the observed shift in synaptic responses. Receptor desensitization and receptor saturation were reduced with cyclothiazide (CTZ; $100 \mu \mathrm{M})$ (Diamond and Jahr, 1995) and a commonly used low-affinity AMPA antagonist, $\gamma$-D-glutamylglycine ( $\gamma$-DGG; 1-2 mM) (Liu et al., 1999; Wadiche and Jahr, 2001), respectively. The design of these experiments was similar to that used in several previous studies (Neher and Sakaba, 2001; Scheuss et al., 2002; Taschenberger et al., 2002). Although application of CTZ and $\gamma$-DGG increased the half-width of EPSCs and reduced their amplitude, as expected from previous reports (Diamond and Jahr, 1995; Hjelmstad et al., 1999; Liu et al., 1999), we found no significant effects of CTZ and $\gamma$-DGG on the pattern of synaptic responses to high-frequency trains or on the shift in synaptic responses with temperature $(n=7)$ (supplemental Fig.

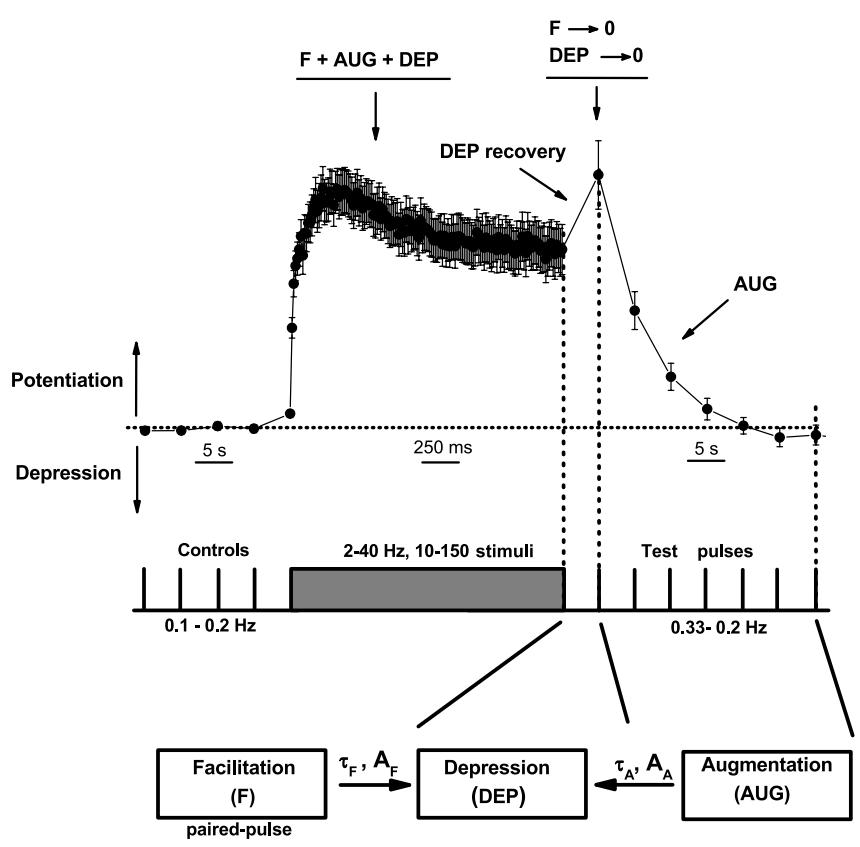

Figure 2. Separation of STP components. Complex response to constant-frequency stimulation (representative fEPSP response to $20 \mathrm{~Hz}, 150$ stimuli is shown) resulted from the interplay of at least three major forms of STP: facilitation (F), augmentation (AUG), and depression (DEP). During the train (shown on an expanded timescale), all components were present simultaneously, and their contributions were difficult to identify. Because of different time courses of decay, however, various components became unmasked at different times after the end of stimulation. Facilitation, which decayed first with a time course of approximately hundreds of milliseconds, was studied separately with a paired-pulse protocol. The second most rapidly decaying process, recovery from DEP, dominated the synaptic response almost immediately after the end of the train $\left[250 \mathrm{~ms}\right.$ to $6 \mathrm{~s}\left(500 \mathrm{~ms}\right.$ to $8 \mathrm{~s}$ at $\left.\left.23^{\circ} \mathrm{C}\right)\right]$. Finally, $\sim 5 \mathrm{~s}\left(\sim 10 \mathrm{~s}\right.$ at $\left.23^{\circ} \mathrm{C}\right)$ after the end of the train, AUG remained the last major STP component, because contributions from rapidly decaying $F$ and DEP became insignificant. We took advantage of this time-based separation of STP components and traced their contributions backward, starting with the slower one. Parameters of the slower components were used in turn to compensate, where necessary, for their contributions to the mixture with the faster components, assuming a multiplicative relationship among the components of potentiation and depression (see Materials and Methods).

4, available at www.jneurosci.org as supplemental material). These results show that under the conditions of our experiments, receptor desensitization and receptor saturation do not play a significant role in the observed effects. Thus, postsynaptic recordings can be reliably used to analyze changes in synaptic responses caused by STP.

\section{Separation of STP components}

The complex response to constant frequency stimulation, shown in Figure 1, resulted from the interplay of at least three major forms of STP that have been identified at hippocampal synapses: depression, facilitation, and augmentation (for review, see (Zucker and Regehr, 2002; Abbott and Regehr, 2004). The contributions of different components to the synaptic response can be difficult to distinguish because all processes are present simultaneously during the train and interact dynamically. We sought to circumvent this problem by taking advantage of the different kinetics of decay exhibited by the various components and by studying each component during a time window in which that component dominated the synaptic response (Fig. 2) (see Materials and Methods). With this approach, we have traced contributions of STP components backward, starting with the slowest one and progressing to the more rapid ones. Parameters of the 


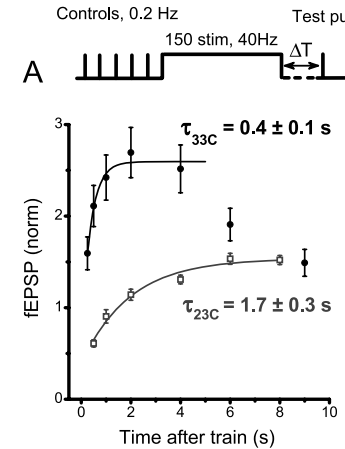

B

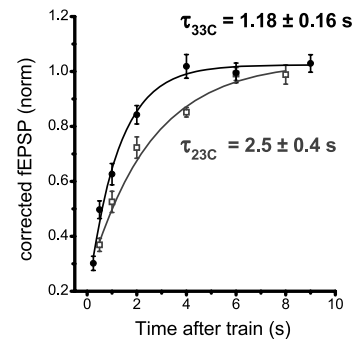

C

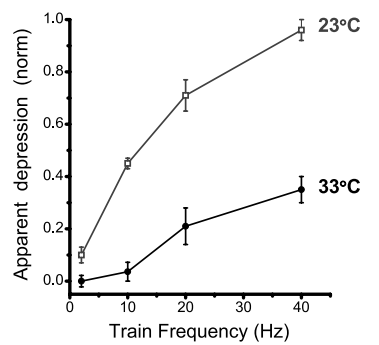

Figure 3. Recovery from depression is much faster at near physiological temperatures. $\boldsymbol{A}$, Single test pulses at different time intervals $(0.25-8 \mathrm{~s})$ after the end of 150 -stimuli, $40 \mathrm{~Hz}$ train revealed a rapid recovery from depression $\left[\right.$ at $23^{\circ} \mathrm{C}(\square)$; at $33^{\circ} \mathrm{C}(\mathbf{O})$; here and throughout], partly obscured by decaying facilitation and augmentation. $\boldsymbol{B}$, Parameters of overlapping components of potentiation were determined from monoexponential fits calculated in each slice, and their contributions to synaptic response during the decay of depression were compensated, assuming a multiplicative relationship among these components. Contributions from the slow component of depression $(\tau \sim 50-60 \mathrm{~s})$ to the time course of recovery from depression were negligible and were not compensated for in these experiments. $\boldsymbol{C}$, The accumulation of apparent depression during 150-stimulus trains at different frequencies $(2-40 \mathrm{~Hz})$ was estimated as a difference between the maximal response and the minimal response during the train, normalized by the maximal response.

slower components could be used in turn to compensate, where necessary, for their contributions to the mixture with the faster components, an approach pioneered by Magleby and Zengel (Magleby, 1979; Magleby and Zengel, 1982). To compensate for contributions from overlapping processes, we assumed that components of potentiation and depression interacted multiplicatively, as had been suggested in previous studies of STP (Magleby, 1979; Magleby and Zengel, 1982; Tsodyks and Markram, 1997; Varela et al., 1997; Markram et al., 1998; Hempel et al., 2000; Okatan and Grossberg, 2000; Brager et al., 2002; Kalkstein and Magleby, 2004) (see Materials and Methods). Because the detailed mechanisms of interactions among STP components are poorly understood and might be more complex than assumed in our analysis, we also determined the extent to which this compensation affected our conclusions (see Discussion). Below, we describe the temperature dependence of STP components, separated as described above but presented in a different order for clarity.

\section{Recovery from depression is much faster at warmer temperatures}

Rapid synaptic depression is commonly interpreted as the depletion of the readily releasable pool (RRP) of vesicles, and therefore the time course of this component is determined by the RRP refilling rate (Zucker and Regehr, 2002; Abbott and Regehr, 2004). We compared the kinetics of depression at 23 and $33^{\circ} \mathrm{C}$ by applying test pulses at different intervals $[250 \mathrm{~ms}$ to $6 \mathrm{~s}$ (or $500 \mathrm{~ms}$ to $8 \mathrm{~s}$ at $23^{\circ} \mathrm{C}$ ) after 150 -stimulus trains at 10 or $40 \mathrm{~Hz}$ (Fig. $3 \mathrm{~A}$ (responses to $40 \mathrm{~Hz}$ trains are shown)]. During this time window, changes in synaptic strength were governed mainly by recovery from depletion (Fig. 2) because facilitation had mostly decayed, whereas longer lasting augmentation changed relatively little; however, contributions from other STP components, mainly decaying augmentation, were evident at $33^{\circ} \mathrm{C}$ (see additional test pulses at 6-9 s) (Fig. 3A). To isolate depression, then, we corrected synaptic responses for contributions from other STP processes by approximating each component with a monoexponential fit and assuming a multiplicative relationship among the components of potentiation and depression (see Materials and Methods).

This analysis revealed a much faster recovery from depression at warmer temperatures than at room temperature $\left(\tau=2.5 \pm 0.4 \mathrm{~s}\right.$ at $23^{\circ} \mathrm{C} ; \tau=$ $1.18 \pm 0.16$ at $\left.33^{\circ} \mathrm{C} ; n=10,8 ; p<0.01\right)$. Perhaps surprisingly, we also found that depletion accumulated to a similar extent at room and near body temperatures $(0.79 \pm 0.03$ and $0.84 \pm 0.04$, respectively; $p>0.49$ ) (Fig. $3 B$ ). This finding may seem inconsistent with the observation that the amount of apparent depression during trains was significantly reduced at warmer temperatures (Fig. 3C). These results can be understood if we consider a situation in which depression accumulates linearly so that the amount of depression at the end of the train is proportional to the product of stimulus frequency, the amount of depression per stimulus, and the time constant of recovery. Because we found that the time constant for recovery is decreased approximately twofold at the higher temperature, the amount of depression per stimulus must increase at warmer temperatures to produce a similar extent of depression at the end of the train. If the mechanism of depression is the depletion of the RRP, this increase in depression per impulse is expected. The fact that at warmer temperatures components of potentiation compensate for depression to maintain elevated levels of transmitter release during constant frequency stimulation (see below) means that the release probability must be higher during trains at $33^{\circ} \mathrm{C}$, and thus the average depletion per impulse is also increased. Thus, the amplitude of apparent depression during trains reflects the interaction of several STP processes rather then synaptic depletion alone. This analysis, also confirmed by whole-cell recordings (supplemental Fig. 3, available at www.jneurosci.org as supplemental material), emphasizes the need for separation of STP components to correctly estimate their contributions to synaptic response.

\section{Both facilitation and augmentation increase strongly with temperature and decay much faster at body temperature} Two major components of STP that increase synaptic strength have been identified in hippocampal synapses: facilitation, with a time course on the order of hundreds of milliseconds, and augmentation, with a time course on the order of a few seconds (Magleby and Zengel, 1976b; Stevens and Wesseling, 1999). We first isolated facilitation with a commonly used paired-pulse protocol that was insufficient to evoke other STP components (Fig. 4) (Zucker and Regehr, 2002). Pairs of pulses at 10-1000 ms intervals revealed a large increase in the amplitude of facilitation with temperature (from $0.26 \pm 0.03$ at $23^{\circ} \mathrm{C}$ to $0.70 \pm 0.05$ at $33^{\circ} \mathrm{C}$; extrapolated to $t=0 ; p<10^{-4} ; n=12,16$; two to five recordings per slice) (Fig. $4 A, B$ ) and an approximately threefold acceleration in the time course of decay (from $465 \pm 79 \mathrm{~ms}$ to $143 \pm 14 \mathrm{~ms}$ ) (Fig. $4 \mathrm{~A}, \mathrm{C}$ ). Both amplitude and time course of facilitation were essentially the same at 33 and $38^{\circ} \mathrm{C}\left(F_{38 \mathrm{C}}=\right.$ $0.66 \pm 0.08 ; \tau_{38 \mathrm{C}}=163 \pm 21 \mathrm{~ms} ; n=5 ; p>0.3$ for both).

Augmentation, a longer-lasting component of potentiation, was evoked by high-frequency stimulation and could be isolated and studied a few seconds after the end of the stimulus train, when both facilitation and depression had decayed completely (Fig. 5A). To compare parameters of augmentation at different temperatures, we applied test pulses at $0.2 \mathrm{~Hz}$ starting $5 \mathrm{~s}$ (or $10 \mathrm{~s}$ at $23^{\circ} \mathrm{C}$ ) after the end of a 150 -stimulus, $10 \mathrm{~Hz}$ train (Fig. $5 A$ ), to 
allow for complete refilling of the RRP $(\tau$ $\sim 2.5 \mathrm{~s}$ at $23^{\circ} \mathrm{C}$ and $\tau \sim 1.2 \mathrm{~s}$ at $33^{\circ} \mathrm{C}$ ). This particular stimulation protocol was chosen because it was insufficient to evoke measurable amounts of the very slow component of depression ( $n=9$ slices; data not shown); therefore, in the selected time window, the reported changes in synaptic strength were associated with pure augmentation. We found that the temperature dependence of augmentation was qualitatively similar to that of facilitation (Fig. 5B-D): augmentation underwent a fivefold increase in amplitude (from $0.76 \pm 0.08$ to $3.9 \pm 0.3 ; n=13,18$; extrapolated to $t=0 ; p<10^{-7}$ ) and decayed approximately seven times faster $(37 \pm 3$ vs $5.6 \pm 0.5 \mathrm{~s} ; p<10^{-5}$ ) as temperature increased from 23 to $33^{\circ} \mathrm{C}$. As with facilitation, parameters of augmentation did not change significantly between 33 and $38^{\circ} \mathrm{C}$ ( $p>0.37$ for both; $n=18,4$ ) (Fig. $5 C, D$ ). Together, these data indicate that both components of potentiation exhibit strong temperature dependence, with a large increase in amplitude and a much faster decay at higher temperatures. In contrast, depression changes little in amplitude but decays twice as fast at higher temperatures (Table 1).

\section{Amplitudes and rates of STP components have different transition points in their temperature dependence}

To determine the range of temperatures at which the transition in properties of STP components occurred, we measured the amplitude and time constant of each process at several intermediate temperatures between 23 and $38^{\circ} \mathrm{C}$ (Fig. 6). In agreement with previous studies suggesting common underling mechanisms of facilitation and augmentation (Zucker and Regehr, 2002), these processes underwent qualitatively similar temperaturedependent transitions in both amplitudes and rates. Interestingly, we also found that for both components of enhancement, the transition in amplitudes occurred several degrees higher $\left(2-4^{\circ} \mathrm{C}\right)$ than the transition in rates, suggesting that different temperature-dependent mechanisms may underlie these changes. The transition point for the rate of depression was shifted $\sim 3^{\circ} \mathrm{C}$ toward warmer temperatures relative to that of facilitation and augmentation, and no significant transition was observed for the amplitude of depression (Fig. 6). For all STP processes, changes in the amplitudes and rates were independent of the direction of the temperature change in the transition range, indicating that no significant hysteretic effects were observed in the temperature dependence of STP components (supplemental Fig. 5, available at www.jneurosci.org as supplemental material).

\section{Pharmacological and mechanistic separation of STP components}

In addition to the kinetics-based method applied above, several other approaches have been used to isolate various STP processes in the NMJ and other preparations. We therefore tested whether these methods are applicable to the hippocampal slice preparation to confirm our observation of the temperature-dependent shift in balance among STP components.

Because elevation in the residual calcium is commonly thought to underlie both facilitation and augmentation, chelating the residual calcium with EGTA-AM should eliminate both components of enhancement (Swandulla et al., 1991; Regehr and
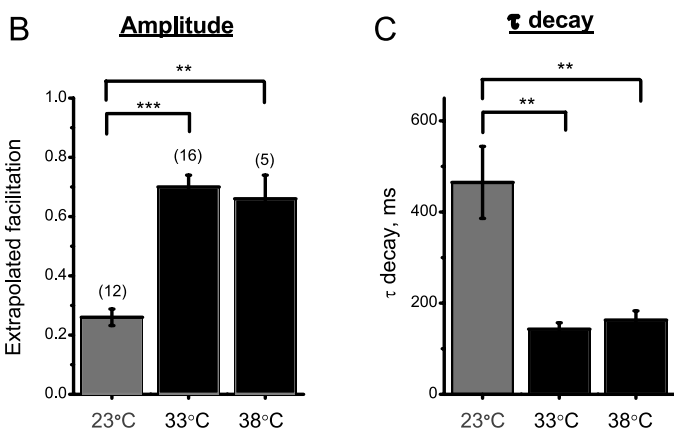
Figure 4. Facilitation increased in amplitude and decayed much faster at $33-38^{\circ} \mathrm{C}$. $\boldsymbol{A}$, Facilitation was measured at $23^{\circ} \mathrm{C}(\square)$
and $33^{\circ} \mathrm{C}(\mathbf{O})$ with a paired-pulse protocol at $10-1000$ ms intervals. Inset, Representative paired-pulse fEPSPs at 23 and $33^{\circ} \mathrm{C} . \boldsymbol{B}$, $\boldsymbol{C}$, Extrapolated amplitude $(\boldsymbol{B})$ and the time course of decay $(\boldsymbol{C})$ of facilitation at 23,33 , and $38^{\circ} \mathrm{C}$. Facilitation was more than two times larger and decayed approximately three times faster at body temperature. Parameters of facilitation did not vary significantly between 33 and $38^{\circ} \mathrm{C}$. ${ }^{* *} p<0.01 ;^{* * *} p<0.001$

Table 1. Amplitudes and rates of STP components have different temperature dependence

\begin{tabular}{lll}
\hline STP process & $\mathbf{Q}_{10}$, Amplitude & $\mathbf{Q}_{10}$, Time course (acceleration) \\
\hline Facilitation & 2.6 & 3.2 \\
Augmentation & 5.1 & 6.6 \\
Depression & 1.1 & 2.1 \\
\hline
\end{tabular}

Delaney, 1994) and be expected to reveal pure depression. We found, however, that although application of EGTA-AM (250 $\mu \mathrm{M})$ completely blocked paired-pulse facilitation after $\sim 30 \mathrm{~min}$ of incubation, it was not sufficient to block augmentation even after 4 h of incubation $(n=6)$ (supplemental Fig. 6, available at www.jneurosci.org as supplemental material). The effects of EGTA-AM on augmentation were nevertheless apparent as it progressively slowed down the increase in synaptic response during trains and prolonged the decay of augmentation with the incubation time, reaching saturation after $\sim 2 \mathrm{~h}$. Therefore, the approach based on the application of EGTA-AM could not be used in our preparation to separate STP components.

Previous studies suggest that augmentation can be isolated by lowering extracellular calcium to decrease the release probability and minimize depression (Dittman and Regehr, 1998). We reduced $[\mathrm{Ca}]_{\mathrm{o}}$ to $0.75 \mathrm{~mm}$ (and increased $\left[\mathrm{Mg}^{2+}\right]_{\mathrm{o}}$ to $2.25 \mathrm{~mm}$ ) and compared the responses to 150 -stimulus trains at 23 and $33^{\circ} \mathrm{C}$. Depression was greatly reduced at both temperatures (supplemental Fig. 7A, available at www.jneurosci.org as supplemental material), as expected from previous studies, whereas the temperature dependence of augmentation remained qualitatively similar to that found above with the kinetic separation of STP components (supplemental Fig. 7, $B$ and $C$, available at www. jneurosci.org as supplemental material). The differences in the $\mathrm{Q}_{10}$ values for the amplitudes and rates of augmentation at 0.75 and $2 \mathrm{~mm}[\mathrm{Ca}]_{\mathrm{o}}$ may reflect the $\mathrm{Ca}^{2+}$ dependence of the processes underlying augmentation (Khananshvili et al., 1995; Blaustein and Lederer, 1999), which are also likely to be temperature dependent (see Discussion). This approach confirmed our findings of the strong temperature dependence of augmentation with a large increase in amplitude and a several-fold acceleration of decay.

Augmentation is also known to be selectively enhanced in the NMJ by $\mathrm{Ba}^{2+}$ application (Zengel and Magleby, 1977; Kalkstein and Magleby, 2004), and this property of $\mathrm{Ba}^{2+}$ can potentially be used as another approach to dissect STP components. We found, however, that $\mathrm{Ba}^{2+}$ application had very different effects in hip- 
A

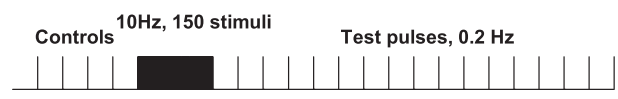

$23^{\circ} \mathrm{C}$

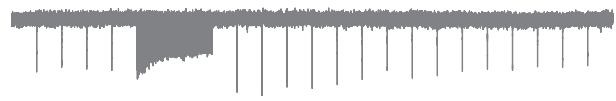

$33^{\circ} \mathrm{C}$

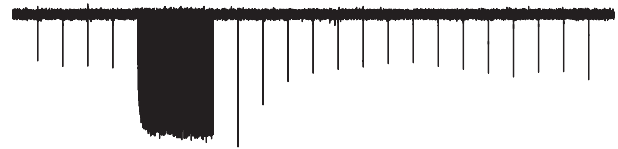

B

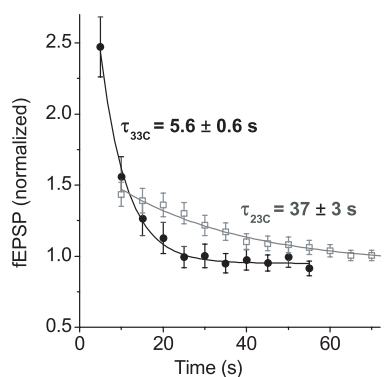

C

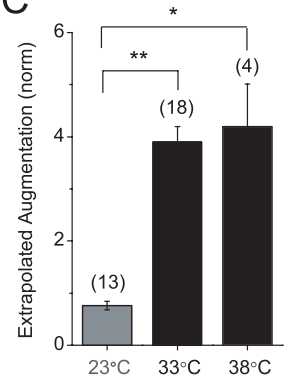

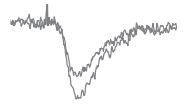

$\mid$\begin{tabular}{l|l}
$0.21 \mathrm{mV}$ \\
$0.3 \mathrm{mV}$
\end{tabular} $10 \mathrm{~s} / 15 \mathrm{~ms}$
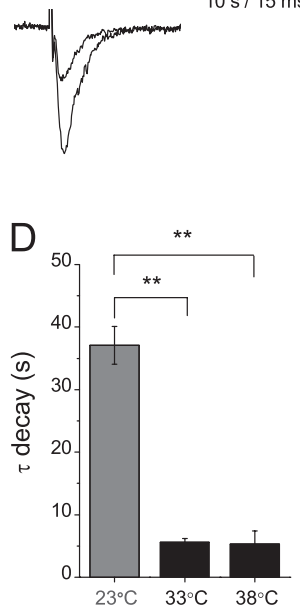

Figure 5. Augmentation increased greatly in amplitude and decayed much faster at $33-38^{\circ} \mathrm{C}$. $\boldsymbol{A}$, Augmentation was monitored with test pulses at $0.2 \mathrm{~Hz}$ after a 150 -stimulus train at $10 \mathrm{~Hz}$. This stimulation protocol was insufficient to evoke the slow component of depression (see Results); therefore, in the selected time window, reported changes in the synaptic strength were associated with pure augmentation. Representative examples of raw fEPSP responses are shown on the top for $23^{\circ} \mathrm{C}$ (gray) and $33^{\circ} \mathrm{C}$ (black) with 15 test pulses after the end of stimulation reflecting the decay of augmentation. For presentation only, the raw traces of train responses were downsampled, and the baseline drifts were subtracted as described in Materials and Methods. Examples of single control and augmented fEPSPs (first test response after each train) are shown on the right for each temperature. $\boldsymbol{B}$, Average augmentation at $23^{\circ} \mathrm{C}(\square)$ and $33^{\circ} \mathrm{C}(\boldsymbol{O})$, measured as shown in $\boldsymbol{A}$. $\mathbf{C}, \boldsymbol{D}$, The amplitude of augmentation extrapolated to $t=0(\boldsymbol{C})$ and the time course of decay $(\boldsymbol{D})$ at 23,33 , and $38^{\circ} \mathrm{C}$. Augmentation was approximately five times larger and decayed approximately seven times faster at $33^{\circ} \mathrm{C}$ than at $23^{\circ} \mathrm{C}\left(p<10^{-5}\right.$ for both). Parameters of augmentation did not change significantly with heating from 33 to $38^{\circ} \mathrm{C}(p>0.37$ for both $) .{ }^{*} p<0.05$; $^{* *} p<0.01$.

pocampal synapses, where it produced strong and long-lasting depression during constant-frequency stimulation $(2-40 \mathrm{~Hz})$ (supplemental Fig. $8 \mathrm{~A}$, available at www.jneurosci.org as supplemental material) and during application of natural stimulus patterns (supplemental Fig. $8 B$, available at www.jneurosci.org as supplemental material). These effects were observed in a wide range of $\mathrm{Ba}^{2+}$ concentrations $(0.6-2 \mathrm{mM})$. Therefore, the action of $\mathrm{Ba}^{2+}$ in the hippocampal synapses is very different from that observed in the NMJ and thus cannot be used to selectively increase augmentation in our preparation. Together, our analysis of different approaches to separation of STP components indicates that, for hippocampal synapses, the kinetics-based method is the most complete approach that allowed dissection of all STP processes.

\section{Much better maintenance of synaptic strength during prolonged use at near body temperatures}

Recent experiments in hippocampal cell cultures have shown that, at body temperature, endocytosis is sufficiently fast to compensate for exocytosis at stimulus rates of up to $\sim 10 \mathrm{~Hz}$ so that synaptic strength is maintained during continued synapse use; however, at room temperature, RRP depletion occurs at frequencies above $\sim 2 \mathrm{~Hz}$ (Fernandez-Alfonso and Ryan, 2004). To examine how a shift of balance among STP components affects the maintenance of synaptic strength at near body temperature, we recorded a set of responses to high-frequency trains (10 and 40
$\mathrm{Hz}$ ) of increasing duration (25-600 stimuli) [Fig. 7 (only trains up to 300 stimuli are shown for clarity)]. As with the results reported for hippocampal cell cultures, synaptic strength was maintained much better at near body temperatures. At least 600 stimuli at $10 \mathrm{~Hz}$ (but only $\sim 15$ at $23^{\circ} \mathrm{C}$ ) (Fig. 1 ) and $\sim 300$ stimuli at $40 \mathrm{~Hz}$ (but only $\sim 4$ at $23^{\circ} \mathrm{C}$ ) could be transmitted at near body temperatures without depressing below control levels (Fig. 7). As shown in Figure 1, with the same frequency of stimulation, whole-cell currents exhibit somewhat less apparent depression and a better maintenance of synaptic transmission than do fEPSPs. Nevertheless, percentage of depressed EPSC responses during high-frequency trains declined $\sim 12$-fold at warmer temperatures ( $n=18$; data not shown).

Together, this set of experiments with constant-frequency stimulation has shown that STP components exhibit strong temperature dependence with a wide range of $\mathrm{Q}_{10}$ factors and that the balance among the components achieved at near body temperatures results in a much better maintenance of synaptic strength during high-frequency trains.

\section{Implications for processing of natural spike trains}

Although the use of constant-frequency trains provides an informative tool for assessing the roles of different STP components in synaptic function, these spike trains are a poor representation of the input that hippocampal synapses would experience in vivo. Therefore, we studied synaptic responses to more physiologically relevant spike patterns recorded in vivo from the hippocampal place cells of behaving rodents (Fenton and Muller, 1998). These patterns, qualitatively like those exhibited by all hippocampal place cells, consist of high-frequency discharges that are also called bursts (Abbott and Regehr, 2004) (average duration of $12.6 \pm 0.9$ action potentials; range, 3-30 action potentials; and average action potential frequency of $28.6 \pm 1.2 \mathrm{~Hz}$; range, $4-62 \mathrm{~Hz}$; data from 69 bursts), separated by periods of low activity (Fig. $8 \mathrm{~A}$, top). Although parameters of individual bursts vary widely among different cells within each hippocampal subfield as well as among ensembles of cells in CA1 and CA3 (Fenton and Muller, 1998; Leutgeb et al., 2004), the firing patterns used here provide a typical structure and a range of ISIs, burst durations, and other statistical properties of the spike patterns that hippocampal synapses may encounter naturally in the circuit. Below we will refer to these spike patterns as "natural" to indicate their origin.

To use natural spike trains recorded at $38^{\circ} \mathrm{C}$ for experiments performed at room temperature, a previous study (Dobrunz and Stevens, 1999) scaled all ISIs by an empirical factor of 3. The choice of a factor 3 , intended to compensate for the differences in the characteristic times of various STP components, corresponded to $\mathrm{Q}_{10} \sim 2$, similar to that reported by other investigators. As described above, however, we found that the $\mathrm{Q}_{10}$ values for different STP components varied significantly (from $\sim 1$ to 
A

Facilitation
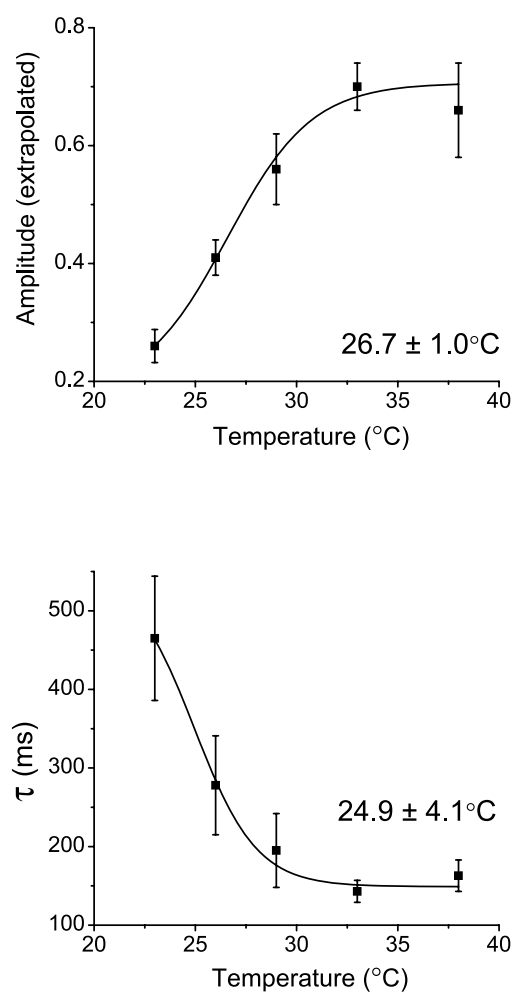

B

Augmentation
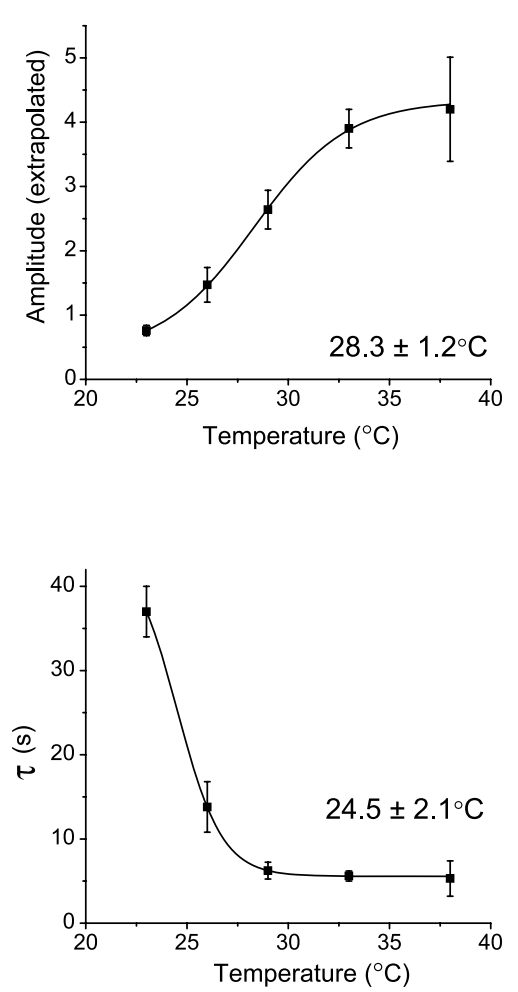

\section{Depression}
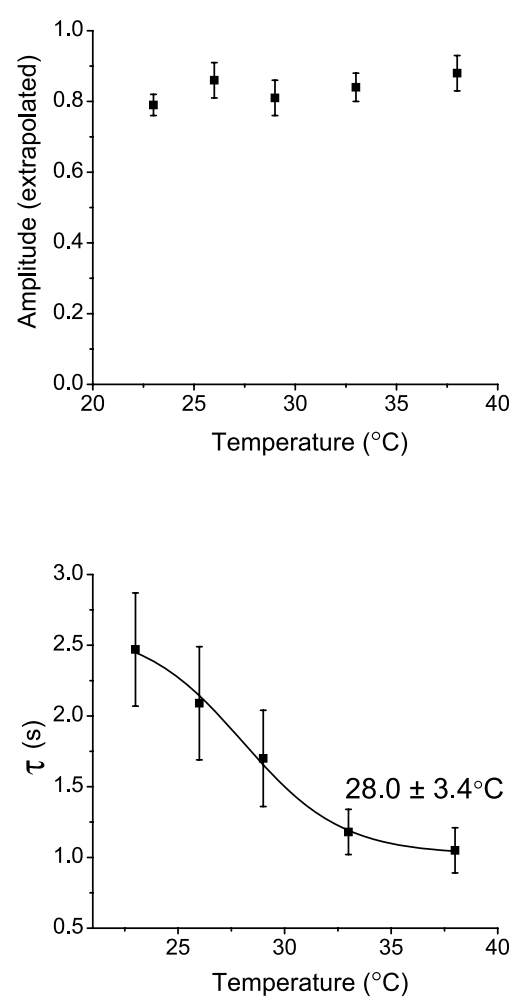

Figure 6. Differential transition points in the temperature dependence of STP components. Extrapolated amplitudes (top panels) and time constants (bottom panels) of facilitation (A), augmentation $(\boldsymbol{B})$, and depression $(\boldsymbol{C})$ were determined as described in Figures $3-5$ in a range of temperatures from 23 to $38^{\circ} \mathrm{C}$. The transition points in the temperature dependence were determined with a sigmoidal Boltzmann equation fit.

$\sim 6$ ), and so the choice of a single scaling factor is problematic. Therefore, we recorded responses at room temperature to unscaled natural input patterns (as is commonly done with the constant-frequency trains) as well as to patterns scaled by a factor of 3 to facilitate comparison with the previous study (Dobrunz and Stevens, 1999).

Figure $8 A$ shows an example of fEPSP recordings from the same slice at 23 and $33^{\circ} \mathrm{C}$ and from a different slice at $38^{\circ} \mathrm{C}$ in response to the natural spike pattern shown above (unscaled at both temperatures). As reported previously (Dobrunz and Stevens, 1999; Dekay et al., 2006), synaptic responses at room temperature underwent large and rapid changes in amplitude that consisted of a variable mixture of facilitation and depression (minimum, $0.48 \pm 0.08$; maximum, $2.04 \pm 0.15 ; n=$ 12) (Fig. $8 A$, top panel). The distribution of changes in synaptic strength during the train had no evident structure, and the ratio of depressed to potentiated responses varied widely from slice to slice (the relative amount of depressed responses varied from 9 to $70 \%$ among different slices; $n=12$ ). This pattern of rapid alteration between potentiation and depression was independent of the ISI scaling because it was also observed during application of natural spike patterns scaled by a factor of 3 ( $n=8$; data not shown, but see Fig. $8 C$ ).

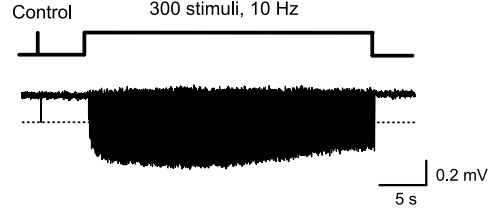

B

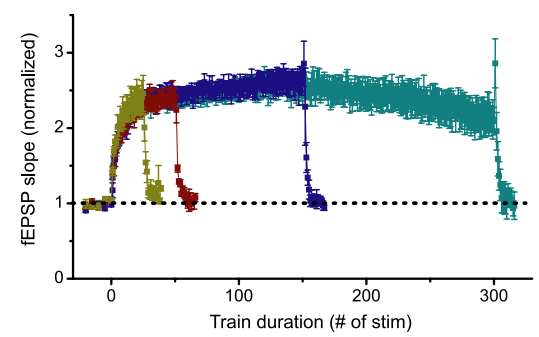

A Control
C

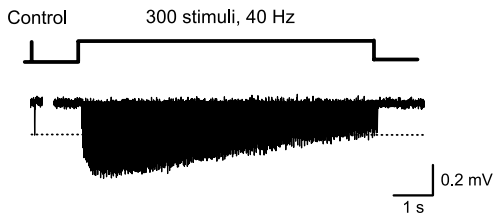

D

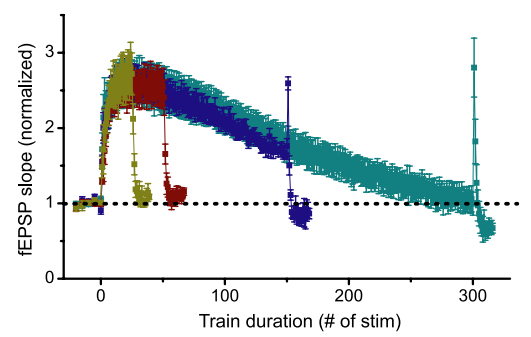

Figure 7. Improved maintenance of synaptic strength during sustained stimulation at higher temperatures. Synaptic responses to trains of different duration (green traces, 25 stimuli; red traces, 50 stimuli; blue traces, 150 stimuli; cyan traces, 300 stimuli) at $10 \mathrm{~Hz}(\boldsymbol{A}, \boldsymbol{B})$ and $40 \mathrm{~Hz}(\boldsymbol{C}, \boldsymbol{D})$ were recorded to evaluate the ability to maintain synaptic strength during prolonged synaptic use at near body temperatures $(n=5)$. Representative fEPSP responses to 300 -stimulus trains at $10 \mathrm{~Hz}(\boldsymbol{A})$ or $40 \mathrm{~Hz}(\boldsymbol{C})$ at $33^{\circ} \mathrm{C}$ are shown on the top, and the average normalized fEPSP slopes for $10 \mathrm{~Hz}(\boldsymbol{B})$ and $40 \mathrm{~Hz}(\boldsymbol{D})$ trains are plotted below. The raw traces were processed for presentation only as described in Materials and Methods.

As expected from the strong temperature dependence of STP components, the response to natural stimulation underwent large changes with heating to $33-38^{\circ} \mathrm{C}$ (Fig. $8 \mathrm{~A}$, middle and bottom panels). Although the absolute amplitude of changes was similar to that at $23^{\circ} \mathrm{C}\left(2.52 \pm 0.17\right.$ at $23^{\circ} \mathrm{C}$ vs $2.57 \pm 0.12$ at $33^{\circ} \mathrm{C}$; $p>0.8 ; n=12,35)$, changes in synaptic strength were "shifted 
A
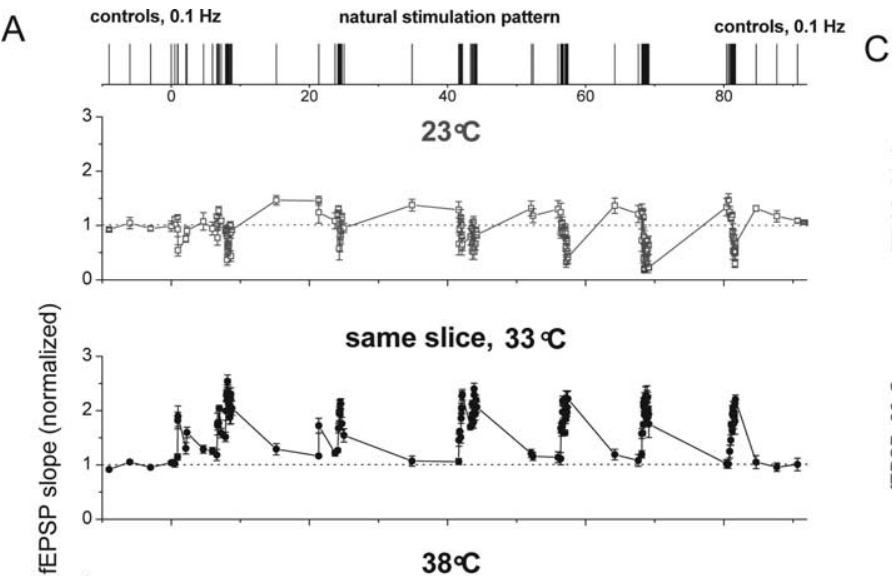

B
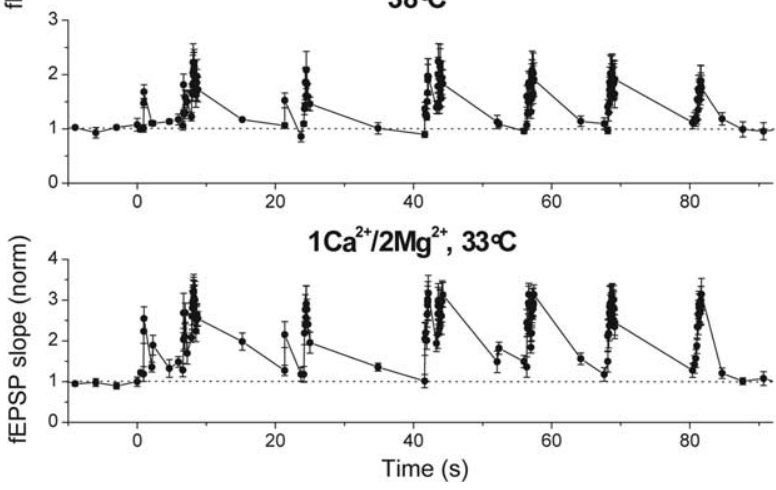

Figure 8. Implications for processing of natural stimulation patterns. $A$, A representation of a natural stimulation pattern with each line depicting a spike (top). fEPSP responses to natural spike patterns (initial slope as a function of time) at $23^{\circ} \mathrm{C}$ (gray trace, top) and $33^{\circ} \mathrm{C}$ (black trace, middle) from the same slice and at $38^{\circ} \mathrm{C}$ from a different slice (black trace, bottom). Each point was an average of four to five train presentations, and each presentation was separated by at least 2 min of controls at $0.1 \mathrm{~Hz}$. The response changed dramatically with heating from 23 to $33^{\circ} \mathrm{C}$ in the same slice but remained the same at 33 and $38^{\circ} \mathrm{C}$ even between different slices. $B, A t 33^{\circ} \mathrm{C}$, the response to natural stimulation was the same in the more physiological $1 \mathrm{~mm}\left[\mathrm{Ca}^{2+}\right]_{0}$ as it was in $2 \mathrm{~mm}\left[\mathrm{Ca}^{2+}\right]_{0}$. C, Changes in synaptic strength during presentation of the same natural stimulation pattern are plotted point by point versus each other for two different conditions: $23^{\circ} \mathrm{C}$ versus $33^{\circ} \mathrm{C}$ (unscaled pattern, top); $23^{\circ} \mathrm{C}$ (pattern scaled $\times 3$; see Results) versus $33^{\circ} \mathrm{C}$ (middle); $38^{\circ} \mathrm{C}$ versus $33^{\circ} \mathrm{C}$ (bottom). The $R$ value was determined with linear regression. $\boldsymbol{D}$, Same as $\boldsymbol{C}$, but for $1 \mathrm{~mm}\left[\mathrm{Ca}^{2+}\right]_{0}$ at $33^{\circ} \mathrm{C}$ versus $2 \mathrm{~mm}\left[\mathrm{Ca}^{2+}\right]_{0}$ at $33^{\circ} \mathrm{C}$.

up" at $33^{\circ} \mathrm{C}$ so that $>98.6 \pm 2.1 \%$ (mean $\left.\pm \mathrm{SD} ; n=35\right)$ of response amplitudes were at or above the control levels, indicating the absence of depressed responses at any time during the train (Fig. $8 \mathrm{~A}$, middle panel). Moreover, a robust pattern of synaptic responses emerged at higher temperatures (Fig. $8 \mathrm{~A}$, middle and bottom panels). Synaptic responses became a function of the spike pattern alone as they consisted of large and rapidly saturating increases in synaptic strength during spike bursts $(2.05 \pm 0.09$ times; range, $1.3-2.9 ; n=35$ ) that decayed to control levels during periods of low activity between the bursts. This general structure of synaptic response at warmer temperatures was observed with all natural stimulation patterns tested (six different patterns; $n=35$ slices and 36 cells). Thus, at higher temperatures, STP works predictably to increase synaptic transmission selectively during high-frequency spike bursts. Together, these data show that the synaptic response to natural stimulation shifts from a variable mixture of potentiation and depression at room temperature to a robust and depression-free filtering pattern at higher temperatures.

\section{The shift in synaptic responses to natural spike patterns} occurs mostly over the temperature range of $23-33^{\circ} \mathrm{C}$

To estimate the range of temperatures at which synaptic responses underwent the transition described above, we used a
C
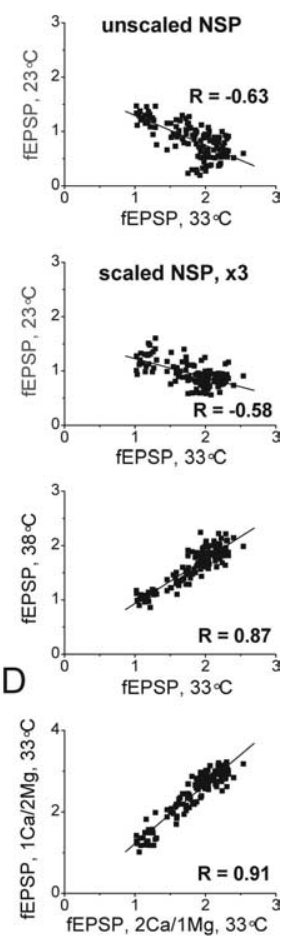

correlation analysis to compare responses to natural stimulation at 23,33 , and $38^{\circ} \mathrm{C}$ (Fig. 8C). Pairs of averaged responses to the same natural spike train from different slices were plotted point-by-point versus each other, and the correlation coefficient $(R)$ was determined with linear regression. The high similarity of responses corresponded to correlation coefficient values close to 1 . As in experiments with constant-frequency stimulation (Fig. 1), synaptic responses were highly correlated in the temperature range of $33-38^{\circ} \mathrm{C}$ (Fig. $8 C)\left(R_{33-38 \mathrm{C}}=0.85 \pm 0.02 ; 16\right.$ randomly selected pairs), but only a weak (and negative) correlation was found between responses at 23 and $33^{\circ} \mathrm{C}\left(R_{33-23 \mathrm{C}}=\right.$ $-0.55 \pm 0.04 ; 22$ randomly selected pairs). These data confirm our results obtained with constant-frequency stimulation that most of the temperature-dependent shift in synaptic response occurs in the $23-33^{\circ} \mathrm{C}$ range.

The pattern of synaptic response at $33^{\circ} \mathrm{C}$ is conserved across a wide range of calcium concentrations

The physiological extracellular calcium concentration $\left(\left[\mathrm{Ca}^{2+}\right]_{\mathrm{o}}\right)$ in the brain is known to be $\sim 1.2 \mathrm{~mm}$ (Jones and Keep, 1988; Brumberg et al., 2000) rather than 2 $\mathrm{mm}$, as commonly used in laboratory experiments. Therefore, we attempted to mimic physiologically relevant conditions more closely by recording responses to natural spike trains in $1 \mathrm{~mm}\left[\mathrm{Ca}^{2+}\right]_{\mathrm{o}}$ (and $\left.2 \mathrm{~mm}\left[\mathrm{Mg}^{2+}\right]_{\mathrm{o}}\right)$. Synaptic responses had the same pattern in $1 \mathrm{mM}\left[\mathrm{Ca}^{2+}\right]_{\mathrm{o}}$ and 2 $\mathrm{mm}\left[\mathrm{Ca}^{2+}\right]_{\mathrm{o}}($ Fig. $8 B, D)(R=0.88 \pm 0.01$;

30 randomly selected pairs), whereas the average increase during bursts was significantly larger in $1 \mathrm{mM}\left[\mathrm{Ca}^{2+}\right]_{\mathrm{o}}(3.10 \pm 0.24$ vs $2.05 \pm 0.09 ; p<0.005 ; n=7,35)$. This trend continued at even lower extracellular calcium $\left(0.6-0.7 \mathrm{~mm}[\mathrm{Ca}]_{\mathrm{o}}\right.$ and $2.4 \mathrm{~mm}$ $[\mathrm{Mg}]_{\mathrm{o}}$ ), with the preservation of the synaptic response structure $(R=0.81 \pm 0.02 ; 24$ randomly selected pairs $)$ and an even larger average increase during bursts, reaching $7.2 \pm 1.6(p<0.05 ; n=$ 4 ; data not shown). These data demonstrate that the robust pattern of synaptic response, one that becomes evident at near body temperature because of a precise balance of STP components, is highly conserved across different experimental conditions, including not only a range of temperatures $\left(33-38^{\circ} \mathrm{C}\right)$ but also at least a threefold range of calcium concentrations $(0.6-2 \mathrm{mM})$.

\section{Responses to natural stimulation are significantly more reproducible at $33-38^{\circ} \mathrm{C}$ than at $23^{\circ} \mathrm{C}$}

To further test the robustness of excitatory synaptic responses to natural stimulation at different temperatures, we compared the reproducibility of whole-cell and fEPSP recordings within single cells or slices as well as across different cells, slices, and animals for the same natural spike train. To facilitate this comparison, we plotted the data from Figure $8 \mathrm{~A}$ versus stimulus number rather than time, so that closely spaced points during the bursts could be compared more easily (Fig. 9A). As with the findings reported in 
previous studies (Dobrunz and Stevens, 1999; Dekay et al., 2006), responses to natural spike trains at room temperature were highly conserved within the same slice for both unscaled and scaled spike patterns $[R=0.82 \pm 0.02(R=0.85 \pm 0.03$ for $3 \times$ scaled patterns); $n=12,7 ; 3$ different patterns tested], but were significantly less reproducible among different slices $[R=$ $0.63 \pm 0.06(R=0.65 \pm 0.05$ for $3 \times$ patterns); $p<0.01$ for both; $n=30,21$ pairs] (Fig. 9D, left panels). Similar results were obtained with whole-cell recordings $(R=$ $0.58 \pm 0.03$ within cells; $n=12$; and $R=$ $0.38 \pm 0.05$ across cells; $n=16$ random pairs), and there was no strong correlation between EPSC and fEPSP responses (Fig. 9 , compare $A, B)(R=0.13 \pm 0.07 ; n=15$ pairs; $p>0.47$ compared with noncorrelated responses). Notice that there is a higher response correlation in fEPSP recordings than in EPSC recordings. This likely reflects the high intrinsic variability of whole-cell responses, which is significantly reduced in field potential recordings because of the averaging across many cells. The high variability of responses at room temperature is illustrated in Figure 9C (left panel): three whole-cell and three fEPSP recordings at $23^{\circ} \mathrm{C}$, all from different animals, are superimposed in the same graph and bear little resemblance to each other. Therefore, as has been reported previously (Dobrunz and Stevens, 1999), at room temperature, synaptic responses to natural stimulation vary significantly among different cells, slices, and animals.

In contrast, at near body temperature, both whole-cell and fEPSP recordings were highly conserved within single cells $(R=0.75 \pm 0.02 ; n=36$; five patterns tested $)$ or single slices $(R=$ $0.90 \pm 0.01 ; n=35$; six patterns tested) as well as across different cells $(R=0.81 \pm 0.02 ; n=36)$, slices, and animals $(R=0.91 \pm$ $0.01 ; n=35$ slices from 14 animals; six patterns tested) (Fig. $9 A-D$, right panels, $E$ ). The striking robustness of synaptic response at higher temperatures is emphasized in Figure $9 C$ (right panel), where three whole-cell recordings and three fEPSP recordings, all from different animals, are superimposed on the same graph and are virtually the same (EPSC and fEPSP responses were highly correlated, with $R=0.81 \pm 0.01 ; 60$ random pairs; five spike patterns). Thus, the selective and predictable synaptic response observed at near physiological temperatures is highly conserved among different cells, slices, and animals, and this conservation of response properties argues for its physiological significance.

\section{Discussion}

In this work, we have isolated and analyzed the contributions of various STP components expressed in excitatory hippocampal synapses during constant frequency and natural stimulation at different temperatures. Our data have shown that, because of a strong but differential temperature dependence, the balance among STP components shifts from dominating depression at room temperature to facilitation- and augmentation-driven potentiation at body temperature. This shift results in a greatly improved maintenance of synaptic strength during prolonged stimulation and qualitatively changes the synaptic response to natural spike trains. The highly conserved filtering pattern observed during natural stimulation at higher temperatures suggests that the fine balance among STP components, achieved only at near physiological temperatures, is required for the robust and physiologically relevant STP function during the processing of realistic spike trains.

Elucidating the functional roles of STP components has been complicated by the presence of multiple overlapping processes during synaptic activity. Here we took advantage of the large difference in the decay kinetics of various STP components to separate their contributions to synaptic modulation. This approach is based on two considerations. (1) Different STP components can be studied during appropriate time windows, during which a particular process dominates changes in synaptic response (Fig. 2); and (2) contributions from the overlapping processes can be corrected for assuming a multiplicative relationship among the components. The validity of the first assumption is supported by our additional analysis, in which the entire data, rather than different time windows, are fitted with Equation 1, 
yielding essentially the same results (see Materials and Methods). However, because the relationships among STP components are not completely understood and probably more complex than assumed in our analysis, it is important to determine the extent to which the second assumption and the associated correction for the overlapping STP components affect our conclusions. Examination of the data reveals that only in the case of depression are the estimates for the temperature-dependent effects significantly altered by the correction (Fig. 3). The observed accelerated recovery from depression with temperature is significant, however, in both cases $(p<0.01)$, and our estimate for the $Q_{10}$ value of this process $(2.1 \pm 0.5)$ fits well with the previously published values $\left(\mathrm{Q}_{10} \sim 2-3\right)$ (Dinkelacker et al., 2000; Pyott and Rosenmund, 2002; Fernandez-Alfonso and Ryan, 2004; Micheva and Smith, 2005; Kushmerick et al., 2006). For all other STP components, the correction is either not required or the amplitudes of temperature-dependent effects are significantly larger than the changes introduced by the correction. Thus, the assumption of multiplicative relationships among STP components does not appreciably affect our conclusions.

The approach applied here to analyze the balance among STP components at different temperatures revealed a diminishing role of depression in the direct modulation of synaptic response at higher temperatures and an increasing dominance of facilitation and augmentation (Fig. 1). Our experiments do not allow us to elucidate the cell biological mechanisms of these temperaturedependent changes; nevertheless, our current understanding of the mechanisms underlying STP processes suggests that the decreasing role of depression originates from accelerated vesicle retrieval and a much faster replenishment of the RRP at higher temperatures (Pyott and Rosenmund, 2002; Fernandez-Alfonso and Ryan, 2004). In the case of facilitation and augmentation, the strong temperature dependence of the amplitudes of these processes may arise, in part, from a larger $\mathrm{Ca}^{2+}$ influx through $\mathrm{Ca}^{2+}$ channels that has been shown to increase with temperature several-fold (Taylor, 1988; McAllister-Williams and Kelly, 1995). Hippocampal neurons also express high levels of the temperature-gated vanilloid receptors (Toth et al., 2005) that are known to affect $\mathrm{Ca}^{2+}$ homeostasis and may have an effect on the amplitudes of facilitation and augmentation by altering basal $\mathrm{Ca}^{2+}$ levels (Guatteo et al., 2005). In addition to a large increase in amplitude with temperature, both components of enhancement exhibited a several-fold acceleration of decay (Figs. 4, 5). These temperature-dependent changes may result from the acceleration of calcium-clearing mechanisms, such as the activity of $\mathrm{Na}^{+} / \mathrm{Ca}^{2+}$ exchanger, which increases with temperature approximately threefold $\left(\mathrm{Q}_{10}\right)$ (Powell et al., 1993; Khananshvili et al., 1995). The $\mathrm{Ca}^{2+}$ dependence of the $\mathrm{Na}^{+} / \mathrm{Ca}^{2+}$ exchange rate also varies with temperature (Khananshvili et al., 1995; Blaustein and Lederer, 1999) and may contribute to the differences in the $\mathrm{Q}_{10}$ values of the two components because they are typically observed at different intracellular $\mathrm{Ca}^{2+}$ levels (Delaney and Tank, 1994).

The temperature-dependent shift among STP components occurred in parallel with a greatly improved maintenance of synaptic strength during continuous synaptic use. At least 10 times as many spikes could be transmitted at higher temperatures without depressing below control levels (Figs. 1, 7). Considering a weak temperature dependence of the basal release probability in hippocampal synapses (Pyott and Rosenmund, 2002), our data suggest that better maintenance of synaptic strength is likely a consequence of the fine balance among STP components achieved at higher temperatures. These results are in agreement with the recent findings in hippocampal cell cultures (Pyott and Rosenmund, 2002; Fernandez-Alfonso and Ryan, 2004), and may be a widespread synaptic property, because a similar effect of temperature has been also found in such structurally and physiologically different types of synapses, as the calyx of Held (Taschenberger and von Gersdorff, 2000) and end-bulb synapses in the avian nucleus magnocellularis (Brenowitz et al., 1998).

The most striking effect of temperature observed here is the large change in the processing of natural spike trains with heating from 23 to $33-38^{\circ} \mathrm{C}$. A combination of several effects can account for these temperature-dependent changes. First, cooling to $23^{\circ} \mathrm{C}$ has been shown to affect several important synaptic properties, including spike generation (Stevens and Zador, 1998; Volgushev et al., 2000), RRP size, and kinetics of exocytosis and endocytosis (Pyott and Rosenmund, 2002; Fernandez-Alfonso and Ryan, 2004; Micheva and Smith, 2005; Kushmerick et al., 2006), as well as the progressive degradation of dendritic spine structure and motility with cooling time (Roelandse and Matus, 2004). The variability in potentiation and depression, observed during natural stimulation at $23^{\circ} \mathrm{C}$, may reflect, in part, the different extent to which these structural and physiological changes have taken place, because the duration of cooling varies in preparations from the same as well as different animals. Indeed, we found consistent (although not statistically significant) changes in the amplitudes of all three STP components with cooling time $(\sim 45,15$, and $7 \%$ increase in the amplitudes of facilitation, augmentation, and depression, respectively). These changes had an impact on the overall structure of synaptic responses to natural stimulation at room temperature as they shifted the relative number of facilitated and depressed responses during the trains (from $49 \%$ of depressed responses to 34\%). However, prolonged cooling had little effect on natural spike train responses at $33-38^{\circ} \mathrm{C}$, because depression was always masked during natural stimulation at these temperatures, and the overall structure of synaptic responses remained largely unaffected. In addition to the effect of different cooling times, we also found an overall larger variability in the parameters of STP components at $23^{\circ} \mathrm{C}$ than at $33^{\circ} \mathrm{C}$. This included both the amplitude and time constant of facilitation ( $\sim 60$ and $\sim 50 \%$ increase in coefficient of variation, respectively) and the amplitude of augmentation ( $\sim 25 \%$ increase). Thus, the reduced variability in the parameters of STP components also contributes to the higher reproducibility of natural spike train responses at warmer temperatures. Finally, another source of variability of STP at room temperature is suggested by the finding that the ratio of facilitation and depression observed during natural spike trains at $23^{\circ} \mathrm{C}$ changed dramatically with the animals' age (postnatal days 12-35) (Dekay et al., 2006). As a result, the responses to natural stimulation were poorly correlated among animals of different ages. Here we found that this was not the case at $33-38^{\circ} \mathrm{C}$, where no depression was observed at any time during natural spike trains independently of the animals' age, in a comparable range of postnatal days 1435. Moreover, the animals' age had no significant effect on response correlation at higher temperatures: the correlation was similarly strong for animals of the same and different ages $(p>0.6)$. Thus the improved reproducibility of responses at higher temperatures may also reflect the developmental changes in expression of facilitation and depression at room temperature that introduce much less variability at higher temperatures, where apparent depression during natural spike trains is insignificant. 
An important consequence of this temperature-dependent shift is the appearance of a physiologically relevant pattern of synaptic response to natural stimulation, obscured at room temperature by dominating depression. Unlike responses at $23^{\circ} \mathrm{C}$, this pattern can be predicted from the structure of the input spike train alone: at higher temperatures, STP acts to amplify synaptic transmission selectively during spike bursts (Fig. 8). The physiological significance of this burst-amplification pattern is suggested by the finding that it is highly conserved across different cells, slices, and animals and under various physiological conditions. Its possible functional role is further emphasized by the fact that high-frequency spike bursts signal hippocampal place fields that carry information about the animal's position in the environment (O'Keefe and Dostrovsky, 1971). Therefore, at higher temperatures, STP in excitatory hippocampal synapses may act to amplify the specific information associated with the place field of the input neuron.

In summary, we found that components of STP undergo a temperature-dependent shift of balance that results in a much better maintenance of synaptic strength at higher temperatures and reveals a highly conserved and predictable pattern of synaptic response to natural stimulation.

\section{References}

Abbott LF, Regehr WG (2004) Synaptic computation. Nature 431:796-803.

Abbott LF, Varela JA, Sen K, Nelson SB (1997) Synaptic depression and cortical gain control. Science 275:220-224.

Blaustein MP, Lederer WJ (1999) Sodium/calcium exchange: its physiological implications. Physiol Rev 79:763-854.

Bolshakov VY, Siegelbaum SA (1995) Regulation of hippocampal transmitter release during development and long-term potentiation. Science 269:1730-1734.

Brager DH, Capogna M, Thompson SM (2002) Short-term synaptic plasticity, simulation of nerve terminal dynamics, and the effects of protein kinase C activation in rat hippocampus. J Physiol (Lond) 541:545-559.

Brenowitz S, David J, Trussell L (1998) Enhancement of synaptic efficacy by presynaptic $\mathrm{GABA}_{\mathrm{B}}$ receptors. Neuron 20:135-141.

Brumberg JC, Nowak LG, McCormick DA (2000) Ionic mechanisms underlying repetitive high-frequency burst firing in supragranular cortical neurons. J Neurosci 20:4829-4843.

Chung S, Li X, Nelson SB (2002) Short-term depression at thalamocortical synapses contributes to rapid adaptation of cortical sensory responses in vivo. Neuron 34:437-446.

Cook DL, Schwindt PC, Grande LA, Spain WJ (2003) Synaptic depression in the localization of sound. Nature 421:66-70.

Dekay JG, Chang TC, Mills N, Speed HE, Dobrunz LE (2006) Responses of excitatory hippocampal synapses to natural stimulus patterns reveal a decrease in short-term facilitation and increase in short-term depression during postnatal development. Hippocampus 16:66-79.

Delaney KR, Tank DW (1994) A quantitative measurement of the dependence of short-term synaptic enhancement on presynaptic residual calcium. J Neurosci 14:5885-5902.

Diamond JS, Jahr CE (1995) Asynchronous release of synaptic vesicles determines the time course of the AMPA receptor-mediated EPSC. Neuron 15:1097-1107.

Dinkelacker V, Voets T, Neher E, Moser T (2000) The readily releasable pool of vesicles in chromaffin cells is replenished in a temperaturedependent manner and transiently overfills at $37^{\circ} \mathrm{C}$. J Neurosci 20:8377-8383.

Dittman JS, Regehr WG (1998) Calcium dependence and recovery kinetics of presynaptic depression at the climbing fiber to Purkinje cell synapse. J Neurosci 18:6147-6162.

Dittman JS, Kreitzer AC, Regehr WG (2000) Interplay between facilitation, depression, and residual calcium at three presynaptic terminals. J Neurosci 20:1374-1385.

Dobrunz LE, Stevens CF (1997) Heterogeneity of release probability, facilitation, and depletion at central synapses. Neuron 18:995-1008.

Dobrunz LE, Stevens CF (1999) Response of hippocampal synapses to natural stimulation patterns. Neuron 22:157-166.
Fenton AA, Muller RU (1998) Place cell discharge is extremely variable during individual passes of the rat through the firing field. Proc Natl Acad Sci USA 95:3182-3187.

Fernandez-Alfonso T, Ryan TA (2004) The kinetics of synaptic vesicle pool depletion at CNS synaptic terminals. Neuron 41:943-953.

Guatteo E, Chung KK, Bowala TK, Bernardi G, Mercuri NB, Lipski J (2005) Temperature sensitivity of dopaminergic neurons of the substantia nigra pars compacta: involvement of transient receptor potential channels. J Neurophysiol 94:3069-3080.

Hardingham NR, Larkman AU (1998) Rapid report: the reliability of excitatory synaptic transmission in slices of rat visual cortex in vitro is temperature dependent. J Physiol (Lond) 507:249-256.

Hempel CM, Hartman KH, Wang XJ, Turrigiano GG, Nelson SB (2000) Multiple forms of short-term plasticity at excitatory synapses in rat medial prefrontal cortex. J Neurophysiol 83:3031-3041.

Hjelmstad GO, Isaac JT, Nicoll RA, Malenka RC (1999) Lack of AMPA receptor desensitization during basal synaptic transmission in the hippocampal slice. J Neurophysiol 81:3096-3099.

Hsia AY, Malenka RC, Nicoll RA (1998) Development of excitatory circuitry in the hippocampus. J Neurophysiol 79:2013-2024.

Jones HC, Keep RF (1988) Brain fluid calcium concentration and response to acute hypercalcaemia during development in the rat. J Physiol (Lond) 402:579-593.

Kalkstein JM, Magleby KL (2004) Augmentation increases vesicular release probability in the presence of masking depression at the frog neuromuscular junction. J Neurosci 24:11391-11403.

Khananshvili D, Shaulov G, Weil-Maslansky E (1995) Rate-limiting mechanisms of exchange reactions in the cardiac sarcolemma $\mathrm{Na}(+)-\mathrm{Ca} 2+$ exchanger. Biochemistry 34:10290-10297.

Kushmerick C, Renden R, von Gersdorff H (2006) Physiological temperatures reduce the rate of vesicle pool depletion and short-term depression via an acceleration of vesicle recruitment. J Neurosci 26:1366-1377.

Leutgeb S, Leutgeb JK, Treves A, Moser MB, Moser EI (2004) Distinct ensemble codes in hippocampal areas CA3 and CA1. Science 305:1295-1298.

Liu G, Choi S, Tsien RW (1999) Variability of neurotransmitter concentration and nonsaturation of postsynaptic AMPA receptors at synapses in hippocampal cultures and slices. Neuron 22:395-409.

Losonczy A, Zhang L, Shigemoto R, Somogyi P, Nusser Z (2002) Cell type dependence and variability in the short-term plasticity of EPSCs in identified mouse hippocampal interneurones. J Physiol (Lond) 542:193-210.

Magleby KL (1979) Facilitation, augmentation, and potentiation of transmitter release. Prog Brain Res 49:175-182.

Magleby KL, Zengel JE (1976a) Augmentation: a process that acts to increase transmitter release at the frog neuromuscular junction. J Physiol (Lond) 257:449-470.

Magleby KL, Zengel JE (1976b) Long term changes in augmentation, potentiation, and depression of transmitter release as a function of repeated synaptic activity at the frog neuromuscular junction. J Physiol (Lond) 257:471-494.

Magleby KL, Zengel JE (1982) A quantitative description of stimulationinduced changes in transmitter release at the frog neuromuscular junction. J Gen Physiol 80:613-638.

Markram H, Pikus D, Gupta A, Tsodyks M (1998) Potential for multiple mechanisms, phenomena and algorithms for synaptic plasticity at single synapses. Neuropharmacology 37:489-500.

McAllister-Williams RH, Kelly JS (1995) The temperature dependence of high-threshold calcium channel currents recorded from adult rat dorsal raphe neurones. Neuropharmacology 34:1479-1490.

Micheva KD, Smith SJ (2005) Strong effects of subphysiological temperature on the function and plasticity of mammalian presynaptic terminals. J Neurosci 25:7481-7488.

Neher E, Sakaba T (2001) Estimating transmitter release rates from postsynaptic current fluctuations. J Neurosci 21:9638-9654.

Ohliger-Frerking P, Wiebe SP, Staubli U, Frerking M (2003) GABA(B) receptor-mediated presynaptic inhibition has history-dependent effects on synaptic transmission during physiologically relevant spike trains. J Neurosci 23:4809-4814.

Okatan M, Grossberg S (2000) Frequency-dependent synaptic potentiation, depression and spike timing induced by Hebbian pairing in cortical pyramidal neurons. Neural Netw 13:699-708.

O’Keefe J, Dostrovsky J (1971) The hippocampus as a spatial map: prelim- 
inary evidence from unit activity in the freely-moving rat. Brain Res 34:171-175.

Pouille F, Scanziani M (2001) Enforcement of temporal fidelity in pyramidal cells by somatic feed-forward inhibition. Science 293:1159-1163.

Powell T, Noma A, Shioya T, Kozlowski RZ (1993) Turnover rate of the cardiac $\mathrm{Na}(+)-\mathrm{Ca} 2+$ exchanger in guinea-pig ventricular myocytes. J Physiol (Lond) 472:45-53.

Pyott SJ, Rosenmund C (2002) The effects of temperature on vesicular supply and release in autaptic cultures of rat and mouse hippocampal neurons. J Physiol (Lond) 539:523-535.

Regehr WG, Delaney KR (1994) The role of presynaptic calcium in shortterm enhancement at the hippocampal mossy fiber synapse. J Neurosci 14:523-537.

Roelandse M, Matus A (2004) Hypothermia-associated loss of dendritic spines. J Neurosci 24:7843-7847.

Scheuss V, Schneggenburger R, Neher E (2002) Separation of presynaptic and postsynaptic contributions to depression by covariance analysis of successive EPSCs at the calyx of Held synapse. J Neurosci 22:728 -739.

Stevens CF, Wesseling JF (1999) Augmentation is a potentiation of the exocytotic process. Neuron 22:139-146.

Stevens CF, Zador AM (1998) Input synchrony and the irregular firing of cortical neurons. Nat Neurosci 1:210-217.

Sun HY, Lyons SA, Dobrunz LE (2005) Mechanisms of target-cell specific short-term plasticity at Schaffer collateral synapses onto interneurones versus pyramidal cells in juvenile rats. J Physiol (Lond) 568:815-840.

Swandulla D, Hans M, Zipser K, Augustine GJ (1991) Role of residual calcium in synaptic depression and post-tetanic potentiation: fast and slow calcium signaling in nerve terminals. Neuron 7:915-926.
Taschenberger H, von Gersdorff H (2000) Fine-tuning an auditory synapse for speed and fidelity: developmental changes in presynaptic waveform, EPSC kinetics, and synaptic plasticity. J Neurosci 20:9162-9173.

Taschenberger H, Leao RM, Rowland KC, Spirou GA, von Gersdorff $\mathrm{H}$ (2002) Optimizing synaptic architecture and efficiency for highfrequency transmission. Neuron 36:1127-1143.

Taylor WR (1988) Two-suction-electrode voltage-clamp analysis of the sustained calcium current in cat sensory neurones. J Physiol (Lond) 407:405-432.

Toth A, Boczan J, Kedei N, Lizanecz E, Bagi Z, Papp Z, Edes I, Csiba L, Blumberg PM (2005) Expression and distribution of vanilloid receptor 1 (TRPV1) in the adult rat brain. Brain Res Mol Brain Res 135:162-168.

Tsodyks MV, Markram H (1997) The neural code between neocortical pyramidal neurons depends on neurotransmitter release probability. Proc Natl Acad Sci USA 94:719-723.

Varela JA, Sen K, Gibson J, Fost J, Abbott LF, Nelson SB (1997) A quantitative description of short-term plasticity at excitatory synapses in layer $2 / 3$ of rat primary visual cortex. J Neurosci 17:7926-7940.

Volgushev M, Vidyasagar TR, Chistiakova M, Eysel UT (2000) Synaptic transmission in the neocortex during reversible cooling. Neuroscience 98:9-22.

Wadiche JI, Jahr CE (2001) Multivesicular release at climbing fiberPurkinje cell synapses. Neuron 32:301-313.

Zengel JE, Magleby KL (1977) Transmitter release during repetitive stimulation: selective changes produced by $\mathrm{Sr}^{2+}$ and $\mathrm{Ba}^{2+}$. Science 197:67-69.

Zucker RS, Regehr WG (2002) Short-term synaptic plasticity. Annu Rev Physiol 64:355-405. 